\section{Insertion of permanent pacemakers as a day case procedure}

\author{
Guy A Haywood, A John Camm, \\ David E Ward
}

Cardiac Department, St George's Hospital, London SW17 0QT Guy A Haywood, MRCP, research fellow

A John Camm, FRCP, head of department

David E Ward, FRCP consultant cardiologist

Correspondence to: $\mathrm{Dr}$ Ward.

Br Med f 1989;299:1139 procedure.
Inserting permanent pacemakers and discharging the patients on the same day has been reported from the United States ${ }^{1}$ and West Germany ${ }^{2}$ and its safety shown. Reviews in the United Kingdom, however, have suggested that patients should remain in hospital for 24 hours after the procedure. ${ }^{3}$ We aimed to assess the feasibility and safety of management on a day case basis by a randomised controlled study, patients' reaction to such management, and the workload imposed on general practitioners in the month after the

\section{Patients, methods, and results}

Patients with suitable home circumstances and aged over 18 accepted for permanent pacing were randomised to either management on a day care basis or conventional management. Conventional management entailed at least one night as an inpatient after implantation of the pacemaker; day case patients were discharged by early evening on the day of the procedure. Standard implantation procedures were used, with follow up at one month.

Twenty one patients were randomised to day case management and 19 to conventional management. The mean age of each group was 74 . Thirty seven patients received new pacemakers and three received new generators. The relative proportions of the different modes of pacing in the groups managed as day cases and conventionally were similar to the overall proportions at our centre over three months. Two of the day case patients could not be discharged on the day of the procedure, one because an appreciable haematoma developed one hour after implantation and one because her family refused to accept her home that day (despite prior agreement). The remaining 19 patients stayed in hospital for a mean of 5.7 hours, compared with 65.7 hours for the patients managed conventionally. Displacement of an electrode resulting in failure of pacing occurred in one patient in each group. An infection severe enough to require a repeat procedure occurred in one of the patients managed conventionally. There were 11 consultations

with a general practitioner in each group in the month after the procedure.

Using a 10 point scoring system, patients indicated how acceptable they had found the experience overall $(0=$ maximally unacceptable, $10=$ maximally acceptable). The mean score was $9 \cdot 0$ for those managed conventionally and $8 \cdot 7$ for those managed as day cases. When asked whether they had considered themselves ready to go home at the time of discharge three of the day case patients said no compared with two of those managed conventionally. Four of those managed conventionally would have preferred to go home on the day of pacing and four of the day case patients would have preferred to stay.

There were no significant differences in the number of consultations with a general practitioner in the month after pacing; or in the scores from the questionnaire on acceptability, between the two groups (MannWhitney $U$ test). To assess the significance of the complication rates the study would have required 2500 subjects.

\title{
Comment
}

Patients seemed to find implantation of a pacemaker on a day case basis as acceptable as conventional admission; there was no evidence that it had a higher rate of complications or that it imposed a greater burden on general practitioners in the ensuing month.

The difference in cost in our hospital for care in the day ward compared with an acute cardiology bed was roughly $£ 200$ a day. As the mean duration of stay in the group managed conventionally was 2.7 days this reflects an average saving per patient of $£ 540$. If all eligible patients given pacemakers in our centre were managed as day cases about $£ 102000$ would be saved each year. Although the availability of day beds may limit the potential cost benefits, beds in the general ward could be used. Pacing centres with a similar proportion of patients eligible for the procedure might expect to double throughput without increasing the total number of beds used for pacing.

We thank Dr J D Poloniecki for help in the statistical design and analysis of this study and our colleagues Dr C W Pumphrey and Dr D Redwood for enabling us to study their patients.

Belott PH. Outpatient pacemaker procedures. Int f Cardiol 1987;17:169-76. 2 Zegelman $\mathrm{M}$, Kreuzer J, Wagner R. Ambulatory pacemaker surgery-medical and economical advantages. PACE 1986:9:1299-303.

3 Bloomfield P, Miller HC. Permanent pacing. Br Med f 1987-295:741-4.

(Accepted 14 A ugust 1989)

\section{Failure to attend for operation: a comparison between booked admissions and the waiting list system}

\section{P W J Houghton, A J M Brodribb}

Plymouth, Devon

PW J Houghton, СHM, senior registrar

A J M Brodribb, MS, consultant general surgeon

Correspondence to: $\mathrm{Mr} \mathrm{P} \mathrm{W}$ J Houghton, Clinic 3, Level 4, Bristol Royal Infirmary, Bristol BS2 8HW.

BrMed f 1989;299:1139-40
A recent report by the National Audit Office suggested that operating theatres in NHS hospitals are used for only $50-60 \%$ of the time for which they are available.' Many factors are responsible for this, but from a surgeon's point of view probably the most common and frustrating reason, after recurring bed closures, is the failure of patients on the waiting list to attend for their operations when sent for. We compared the numbers of patients who failed to attend for admission when an outpatient booking system and a waiting list system were used to call patients for operation.

\section{Patients, methods, and results}

Two consultant general surgeons working as a firm in this hospital have different systems for admitting patients for operation. One uses a waiting list; after being seen in the outpatient department each patient is placed on this waiting list, the operation being classified as urgent, to be done soon, or routine; there is a separate list for varicose veins. The second surgeon (AJMB) uses a booking system whereby all patients, except those with uncomplicated varicose veins, who are put on a waiting list, are given a date in the clinic for admission for operation. The dates are entered into a diary, which the consultant carries at all times. Each consultant has a similar workload treating comparable 